\title{
O ACESSO À JUSTIÇA COMO DIREITO HUMANO FUNDAMENTAL: A BUSCA DA EFETIVAÇẪO DA RAZOÁVEL DURAÇÃO DO PROCESSO POR MEIO DO PROCESSO ELETRÔNICO

\author{
ACCESS TO JUSTICE AS A FUNDAMENTAL HUMAN RIGHT: THE SEARCH FOR \\ THE EFFECTIVENESS OF THE REASONABLE DURATION OF THE PROCESS \\ THROUGH ELECTRONIC PROCESS
}

Queli Cristiane Schiefelbein da Silva* Fabiana Marion Spengler**

\begin{abstract}
Resumo: O presente artigo buscou demonstrar a importância do processo eletrônico como uma forma de efetivar a duração razoável do processo e o acesso à justiça. Dessa forma, inicialmente, procurou-se apresentar o acesso à justiça como um direito humano fundamental e o mais básico dos direitos humanos, sendo este o garantidor de todos os demais direitos. Analisada a importância da garantia do acesso à justiça, traz-se posteriormente o conceito de tempo e de razoável duração do processo, observando-se brevemente as alterações trazidas pela EC n. 45/2004 e a previsão já existente no Pacto de San José da Costa Rica quanto à garantia de prazo razoável. Por fim, considerando as evoluções tecnológicas, e observando que o Poder Judiciário e o processo precisam acompanhar as transformações da sociedade, o processo eletrônico é apresentado como uma solução para ajudar na busca da efetividade do acesso à justiça e da duração razoável do processo.
\end{abstract}

Palavras-chave: Acesso à justiça. Duração razoável. Processo eletrônico.

\begin{abstract}
This paper demonstrates the importance of the electronic process as a way to accomplish the reasonable duration of the process and access to justice. Thus, initially seeks to provide access to justice as a fundamental human right and the most basic human rights, which is the guarantor of all other rights. Analyzed the importance of ensuring access to justice, then brings up the concept of reasonable time and duration of the process, noting briefly the changes brought by EC n. 45/2004 existing and forecast the Pact of San José, Costa Rica on the guarantee of reasonable time. Finally, considering the technological developments, and in view of the Judiciary and the process must follow the transformations of society, the electronic process is presented as a solution to help in the search for effective access to justice and reasonable duration of the process.
\end{abstract}

Keywords: Access to justice. Reasonable duration. Electronic process.

\footnotetext{
" Mestre em Direitos Humanos pela Universidade Regional do Noroeste do Estado do Rio Grande do Sul (Unijuí), RS; Especialista em Ciências Penais pela Universidade do Sul de Santa Catarina (Unisul), SC; Técnica Judiciária da Justiça Federal do Rio Grande do Sul - Supervisora da Unidade Avançada de Atendimento da Justiça Federal em Ijuí; Rua do Comércio, 3000, Universitário, 98700-000, Ijuí, Rio Grande do Sul, Brasil; quelicss@yahoo.com.br ** Pós-doutora pela Università degli Studi di Roma Ter, Itália; Mestre em Desenvolvimento Regional pela Universidade de Santa Cruz do Sul (Unisc), RS; Professora dos Cursos de Graduação e Pós-graduação lato e stricto sensu da Universidade de Santa Cruz do Sul (Unisc), RS; Professora da Universidade Regional do Noroeste do Estado do Rio Grande do Sul (Unijuí), RS; Avenida Independência, 2293, Universitário, 96815-900, Santa Cruz do Sul, Rio Grande do Sul, Brasil; fabiana.spengler@unijui.edu.br
} 


\section{Introdução}

O acesso à justiça é um direito humano fundamental, pois é a ideia central ao redor da qual convergem todos os princípios e garantias constitucionais. Dessa forma, como garantidor de todos os demais direitos, é necessário que seja de fato garantido o acesso a uma ordem jurídica justa. E para que o acesso à justiça seja de fato efetivo, é necessário que o processo possua uma duração razoável, com resposta ao conflito em tempo adequado, pois de nada adianta uma decisão judicial justa e correta se chegar tarde e se tornar ineficaz. Assim, como uma das formas de efetivação do princípio da celeridade e acesso à justiça, surge a utilização do processo eletrônico.

Com o principal objetivo de proporcionar aos jurisdicionados uma maior celeridade dos procedimentos, o processo eletrônico traz como algumas de suas vantagens a facilidade de acesso à justiça e a agilização da tramitação processual. Entre os principais princípios afetados pela sua utilização estão: o acesso à justiça e a duração razoável do processo. E, na análise prática do funcionamento do processo eletrônico, verifica-se que o Tribunal Regional Federal da $4^{\text {a }}$ Região foi o pioneiro, no Brasil, na implantação do processo eletrônico para todas as ações, razão pela qual pode ser tomado como exemplo e "laboratório" para a análise dos resultados trazidos com a utilização do processo eletrônico e verificar se ele está atingindo os seus objetivos.

Dessa forma, inicialmente, será analisado o conceito de acesso à justiça como um direito humano fundamental, o qual possui como um dos entraves para a sua efetivação a duração do processo. Nesse sentido, será avaliada a questão do tempo do processo, bem como feita uma análise acerca do princípio da celeridade e da razoável duração do processo. Por fim, busca-se demonstrar, por meio da observação da experiência prática trazida pelo Tribunal Regional Federal da $4^{a}$ Região que o processo eletrônico é uma forma de efetivação dos princípios da celeridade e do acesso à justiça.

Para fins de cumprir com tais objetivos, o método de abordagem utilizado foi o dedutivo, partindo da relação entre argumentos gerais, denominados premissas, para argumentos particulares, até se chegar a uma conclusão. Como método de procedimento foi utilizado o método monográfico, a partir de pesquisas e fichamentos em fontes bibliográficas, estudo de estatísticas ligadas ao tema da pesquisa, além de livros e trabalhos relativos ao assunto (VENTURA, 2000).

\section{0 acesso à justiça como direito humano fundamental}

O acesso à justiça é reconhecido atualmente como um direito humano fundamental e, dessa forma, pressuposto para o exercício da cidadania, pois a concretização dos demais direitos fundamentais é inviável sem o acesso à justiça, razão pela qual pode ser chamado de Direito a ter direitos.

Segundo Cintra, Grinover e Dinamarco (2004, p. 33), “[...] o processo deve ser manipulado de modo a propiciar às partes o acesso à justiça, o qual se resolve, 
na expressão muito feliz da doutrina brasileira recente, em acesso à ordem jurídica justa." E essa expressão "acesso à justiça" tem uma difícil definição, pois abrange todos os meios a que se destina a um fim, a saber: a reivindicação dos direitos dos cidadãos e a solução dos litígios dos indivíduos, por meio de um sistema que deve proporcionar e produzir a todos resultados justos (CAPPELLETTI; GARTH, 1988, p. 8). Ainda, nesse sentido, nas palavras de Cichocki Neto (2001, p. 61):

[...] a expressão "acesso à justiça" engloba um conteúdo de largo espectro: parte da simples compreensão do ingresso do indivíduo em juízo, perpassa por aquela que enforca o processo como instrumento para a realização dos direitos individuais, e, por fim, aquela mais ampla, relacionada a uma das funções do próprio Estado a quem compete, não apenas garantir a eficiência do ordenamento jurídico; mas, outrossim, proporcionar a realização da justiça aos cidadãos.

Percebe-se que, segundo Cappelletti e Garth (1988, p. 9-11), o conceito de acesso à justiça sofreu uma transformação importante na passagem dos Estados liberais burgueses dos séculos XVIII e XIX, que tinham procedimentos para a solução de litígios com caráter individualista, para as sociedades modernas, nas quais as ações e relacionamentos assumiram caráter mais coletivo, visto que passaram a reconhecer os direitos e deveres sociais dos governos, comunidades, associações e indivíduos. Dessa forma, a atuação positiva do Estado passou a ser necessária para assegurar o gozo desses direitos sociais básicos e o direito ao acesso efetivo à justiça ganhou corpo à medida que as reformas do Estado de bem-estar social procuraram conceder aos indivíduos novos direitos.

Atualmente prevalece, nos dizeres de Cappelletti e Garth (1988, p. 11-12), o acesso à justiça como requisito fundamental. Nesse sentido:

O direito ao acesso efetivo tem sido progressivamente reconhecido como sendo de importância capital entre os novos direitos individuais e sociais, uma vez que a titularidade de direitos é destituída de sentido, na ausência de mecanismos para sua efetiva reivindicação. $\mathrm{O}$ acesso à justiça pode, portanto, ser encarado como o requisito fundamental - o mais básico dos direitos humanos - de um sistema jurídico moderno e igualitário que pretenda garantir, e não apenas proclamar os direitos de todos.

Cita-se, nos dizeres de Cappelletti e Garth (1988, p. 13), que “O ‘acesso' não é apenas um direito social fundamental, crescentemente reconhecido; ele é, também, necessariamente, o ponto central da moderna processualística. Seu estudo pressupõe um alargamento e aprofundamento dos objetivos e métodos da moderna ciência jurídica."

Percebe-se que o acesso à justiça não é mais tido como a mera admissão do indivíduo ao processo ou possibilidade de ingresso ao juízo, pois de nada adianta permitir ao cidadão o seu acesso e não proporcionar condições para que se obtenha uma sentença justa, eficaz e um processo imparcial. Nesse sentido, com a evolução na busca da melhor maneira de garantir a justiça para todos, a tendência moderna está desenvolvendo as ideias do direito social como forma de acesso por meio dos 
direitos fundamentais de ação e defesa, dentro de um Estado social, no qual a função fundamental do Estado é de promover a plena realização dos valores humanos e, segundo Cintra, Grinover e Dinamarco (2004, p. 25):

[...] deve servir, de um lado, para pôr em destaque a função jurisdicional pacificadora como fator de eliminação dos conflitos que afligem as pessoas e lhes trazem angústia; de outro, para advertir os encarregados do sistema, quanto à necessidade de fazer do processo um meio efetivo para a realização da justiça. Afirma-se que o objetivo-síntese do Estado contemporâneo é o bem comum e, quando se passa ao estudo da jurisdição, é lícito dizer que a projeção particularizada do bem comum nessa área é a pacificação com justiça.

Nesse sentido, na lição de Cintra, Grinover e Dinamarco (2004, p. 33), temos que: "[...] para que haja o efetivo acesso à justiça é indispensável que o maior número possível de pessoas seja admitido a demandar e a defender-se adequadamente [...] mas, para a integralidade do acesso à justiça, é preciso isso e muito mais." Assim, ao continuar, referem os autores que o acesso à justiça é:

[...] a idéia central a que converge toda a oferta constitucional e legal desses princípios e garantias. Assim, (a) oferece-se a mais ampla admissão de pessoas e causas ao processo (universalidade da jurisdição), depois (b) garante-se a todas elas (no cível e no criminal) a observância das regras que consubstanciam o devido processo legal, para que (c) possam participar intensamente da formação do convencimento do juiz que irá julgar a causa (princípio do contraditório), podendo exigir dele a (d) efetividade de uma participação em diálogo -, tudo isso com vistas a preparar uma solução que seja justa, seja capaz de eliminar todo resíduo de insatisfação. Eis a dinâmica dos princípios e garantias do processo, na sua interação teleológica apontada para a pacificação com justiça. (CINTRA; GRINOVER; DINAMARCO, 2004, p. 33-34, grifo do autor).

Seguindo essa ideia, Nalini (2000, p. 19) afirma que "O acesso à justiça deixou de ser tema teórico para encontrar reflexo no texto constitucional e para representar um contínuo esforço de todo o operador jurídico brasileiro, no sentido de alargar a porta da justiça a todos, principalmente os excluídos."

$\mathrm{E}$, nessa perspectiva de direito fundamental de acesso à justiça, verifica-se que no Brasil o principal parâmetro normativo é o princípio da proteção judiciária, também chamado, segundo Silva (2003), de princípio da inafastabilidade do controle jurisdicional, que combinando os princípios do devido processo legal (Artigo $5^{\circ}$, LIV), do contraditório e plenitude de defesa (Artigo $5^{\circ}, \mathrm{LV}$ ) e do direito de acesso à Justiça (Artigo $5^{\circ}, \mathrm{XXXV}$ ) fecham o ciclo das garantias processuais. Salienta-se, todavia, que o princípio da proteção judiciária não deve ser concebido apenas na sua acepção institucional (direito formal de invocar a jurisdição), mas como um princípio garantidor, especialmente a fim de garantir do Judiciário o direito a uma resposta rápida, precisa e justa, capaz de assegurar resultados úteis.

Com tudo isso, observa-se que esse novo enfoque de acesso à justiça traz a ideia de que o princípio da proteção judiciária se constitui um direito humano fundamental de acesso a uma ordem jurídica justa. E o acesso à justiça é o garantidor 
de todos os demais direitos, pois ao seu redor convergem todos os princípios e as garantias constitucionais, razão pela qual é uma maneira de assegurar a efetividade aos direitos de cidadania. Dessa forma, é um direito de suma importância, por ser um direito elementar do cidadão, pelo qual ocorre a materialização da cidadania e a efetivação da dignidade da pessoa humana.

Todavia, embora o acesso à justiça tenha sido aceito como um direito social básico na sociedade moderna, ele carece de efetividade, considerando-se os obstáculos para alcançá-lo, entre os quais se destaca a demora do processo. O interesse em torno do acesso efetivo à Justiça levou, segundo Cappelletti e Garth (1988), a um movimento para soluções práticas, iniciado em 1965. A primeira onda desse movimento pretendia garantir a assistência judiciária gratuita para os pobres; a segunda, maior representatividade na defesa dos interesses difusos, especialmente nas áreas de proteção ambiental e do consumidor; a terceira, mais recente, atribui um novo enfoque ao "acesso à Justiça", modificando o foco para o cidadão e, além de incluir os movimentos anteriores, vai mais adiante, na tentativa de atacar os obstáculos de modo mais articulado e compreensivo, encorajando a realização de reformas, incluindo:

[...] alterações nas formas de procedimento, mudanças nas estruturas dos tribunais ou de novos tribunais, o uso de pessoas leigas ou paraprofissionais, tanto como juízes quanto como defensores, modificações no direito substantivo destinadas a evitar litígios ou facilitar sua solução e a utilização de mecanismos privados ou informais de solução dos litígios. (CAPPELLETTI; GARTH, 1988, p. 71).

Segundo Nalini (2000), o movimento do acesso à justiça é uma solução de compromisso, que não renega o aspecto normativo do direito, mas o enfatiza como elemento de extrema importância, visto que é condição necessária ao conhecimento do fenômeno jurídico, mas não suficiente à sua compreensão total. Nesse sentido, o direito é norma, todavia não se contém todo na positividade. Dessa forma, não pode ser visto de forma isolada, mas como parte integrante de um ordenamento social mais complexo, em conexão com a economia, a moral e a política. Prossegue Nalini (2000, p. 25) afirmando que

\footnotetext{
Dentre os aspectos suscetíveis de análise do movimento de acesso à justiça, é este - o cultural - o mais importante. Compreender que a sociedade já não é idêntica à do momento histórico em que elaborada a codificação, que os anseios por justiça têm uma razão de ser e que o juiz, ainda inserido no presente, deve ter condições de visualizar a situação sob um ângulo de perspectiva constituem ponto decisivo para se extrair dessa tendência objetivos práticos muito definidos.
}

Assim, verifica-se que com essas reformas se procura modificar a estrutura processual e física do Judiciário, em busca da efetivação do direito à justiça. E, de fato, a Constituição Federal de 1988 foi amplamente influenciada pelos movimentos sociais, visto que incorporou um conjunto amplo de garantias e direitos, razão pela qual foi proclamada como a "Constituição Cidadã". Nesse sentido, como bem obser- 
va o autor, a Constituição do Brasil de 1988 é pródiga em exemplos de preceitos demonstradores da intenção de favorecer o acesso de todos os homens ao benefício da justiça, desde o seu primeiro artigo, no inciso III, que estabelece, como fundamento da República, a dignidade da pessoa humana. Para que haja o reconhecimento em plenitude de sua dignidade, quando vulnerada em seus direitos, as pessoas necessitam a via aberta ao Judiciário.

Observa-se, ainda, pelo Artigo $3^{\circ}$ da Constituição Federal, que constitui objetivo fundamental da República do Brasil a construção de uma sociedade livre, justa e solidária, garantindo-se o desenvolvimento nacional, erradicando a pobreza, a marginalização e reduzindo as desigualdades sociais e regionais, bem como promovendo o bem de todos, sem preconceitos de origem, raça, sexo, cor, idade e quaisquer outras formas de discriminação - incisos I, II, III e IV. Assim, há um evidente fortalecimento do princípio da isonomia, conforme assinala Nalini (2000, p. 42):

[...] o art. $5^{\circ}$ ainda contempla o direito de petição em defesa de direitos inciso XXXIV, a - a inafastabilidade do controle jurisdicional de qualquer lesão ou ameaça a direito - inciso XXXV - o processo e sentenciamento pela autoridade judiciária competente - inciso LIII - o devido processo legal - inciso LIV - o contraditório e ampla defesa, com recursos e meios a ela inerentes, seja no processo judicial, seja no administrativo - inciso LV. Assegurou ainda a prestação de assistência jurídica integral e gratuita aos que comprovarem insuficiência de recursos - incisos LXXIV - e trouxe institutos novos, caracterizadores da verdadeira participação popular na administração da justiça: mandado de segurança coletivo, mandado de injunção, habeas data, ação popular e ação privada nos crimes de ação pública, se esta não for intentada no prazo legal - incisos LXX, LXXI, LXXII, LXXIII e LIX, todos do art. $5^{\circ}$ da Lei Maior.

Salienta-se, também, que nos Artigos $6^{\circ}$ a 11 da Constituição Federal houve um elástico reconhecimento dos direitos de segunda dimensão, ou seja, dos direitos sociais, sendo fixados o bem-estar e a justiça social como os objetivos da ordem social, que têm como base o primado do trabalho, conforme o Artigo 193 da Carta Magna Brasileira (NALINI, 2000). Dessa forma, observa-se que os direitos constitutivos da cidadania foram significativamente alargados, pois ao lado dos direitos tradicionais de natureza individual foram incorporados os direitos supraindividuais, ou sociais. E com essa ampliação dos direitos concedidos aos indivíduos ocorre um consequente aumento da litigiosidade; o Judiciário passa a ser requisitado de forma ampla, o que realça ainda mais a incapacidade e as deficiências da estrutura judiciária (SPENGLER; NETO, 2011).

Nesse sentido, um dos principais problemas do Judiciário com essa "explosão" de ações judiciais, após o advento da Carta de 1988, é a morosidade do processo. Por essa razão, o tema acerca do tempo do processo, bem como o princípio da celeridade e o que se entende por razoável duração do processo são relevantes para este estudo, e serão analisados em seção específica, a seguir. 


\section{Tempo do processo: princípio da celeridade e razoável duração}

A partir do novo contexto do direito de acesso à justiça, qual seja, de requisito fundamental de um sistema jurídico contemporâneo e solidário que pretenda não apenas proclamar os direitos de todos, mas especialmente garanti-los de forma efetiva, a questão do tempo de duração do processo assume grande importância, pois o Estado é caracterizado, a priori, pela sua função social, que tem como objetivo assegurar o bem comum e realizar a justiça social. Dessa forma, a demora na prestação jurisdicional descumpre esse objetivo, pois como adverte Rodrigues (2005, p. 285), "[...] não há justiça social quando o Estado, por meio do poder Judiciário, não consegue dar uma pronta e efetiva resposta às demandas que lhe são apresentadas."

Nesse sentido, cumpre ao ordenamento jurídico atender ao pedido daquele que buscar exercer o seu direito à prestação jurisdicional da forma mais completa e eficiente possível. Para isso, é necessário assegurar ao jurisdicionado de forma efetiva o seu direito, dentro de um lapso de tempo razoável, ou seja, é imperioso que a decisão, além de efetiva, seja também tempestiva.

Mas o que é um tempo razoável?

Inicialmente, cabe questionar o que é o tempo. Buscando uma resposta, observa-se que, segundo o minidicionário Houaiss, entre as significações para o termo, está ser um "[...] período contínuo e indefinido no qual os eventos se sucedem e criam no homem a noção de presente, passado e futuro." (HOUAISS; VILLAR, 2008, p. 721). Tentando definir o tempo na concepção atual, Spengler (2010, p. 180) afirma que, simbologicamente, a palavra "tempo" designa "[...] a relação que um grupo de seres vivos dotados de uma capacidade biológica de memória e de síntese estabelecida entre dois ou mais processos, um dos quais é padronizado para servir aos outros como quadro de referência e padrão de medida." Dessa forma, percebe-se que as relações temporais são instituídas em diversos níveis, de múltiplas complexidades.

E como o tempo não se deixa ver, tocar, ouvir, saborear e nem respirar, são criados os relógios para ao menos oferecer orientação ao homem quanto à duração do dia e da noite, pois a "sensação do passar do tempo" tem central importância para os sentimentos de consciência (SPENGLER, 2010). Todavia, a verdadeira medida do tempo, segundo Ost (2005, p. 22), “[...] não é nem relojoeira, nem subjetiva”, como é afirmado por Fernando Pessoa ao referir não saber o que é o tempo. Para Ost (2005), o tempo "sócio-histórico", produto das construções coletivas da história é a medida que se serve simultaneamente para a materialidade do tempo dado e da experiência do tempo vivenciado, reelaborando os seus elementos, ou seja, "[...] dá-lhes as palavras e os instrumentos para se dizer." (OST, 2005, p. 23).

Segundo Spengler (2010), existem diversas noções de tempo; os tempos artificiais são produzidos pela combinação da tecnologia com os ritmos de vida das pessoas. Nesse sentido, a automatização e a robotização das empresas acabaram por romper o tempo tradicional, e a aceleração temporal aproxima o presente do futuro, "[...] conferindo-lhe uma densidade proveniente da quantidade e alcance dessas 
mudanças em curto espaço de tempo." (SPENGLER, 2010, p. 186). Observa-se que na Era Industrial o tempo não poderia ser desperdiçado, pois as máquinas não paravam e os trabalhadores tinham que acompanhar o ritmo. Assim, com a mecanização, houve a aceleração do ritmo de vida das pessoas, sendo necessária a divisão de tarefas (adoção do sistema fordista) para haver economia de tempo, visto que se exigiam resultados em curto prazo e fazer mais no menor tempo possível, a fim de se obter o lucro do sistema capitalista. Dessa forma, com a modernidade, o tempo passou a ser escrito, ter uma história e pode ser mudado e manipulado.

Oportuno salientar a interligação entre o tempo e o direito, pois o direito afeta a temporalização do tempo e este determina a força constituinte do direito. Em termos mais precisos, segundo Ost (1999, p. 14), “[...] o direito temporiza ao passo que o tempo institui." Para Spengler (2010), não existe tempo, direito e sociedade isolados, mas trata-se de uma instituição imaginária, na qual o tempo institui e é instituído, sendo o direito uma instituição temporal.

Já em relação ao tempo e ao processo, que é um ritual, observa-se, inicialmente, que o tempo do processo não é um tempo ordinário. Ele é um tempo contínuo, com um começo e um fim. É um tempo único (não reproduzível) em razão da autoridade do princípio da coisa julgada, que busca a verdade e a garantia de que o acusado/requerido possa se defender. O tempo do processo é resultado de regras processuais e da matéria litigiosa, que impõe o ritmo dos procedimentos, o qual deve integrar as evoluções do litígio. No processo, o tempo é recriado, ou seja, o processo não decorre de um tempo real; "[...] o tempo é muito mais 'longo' para as partes (especialmente o acusado) do que para os profissionais da Justiça." (SPENGLER, 2010, p. 212).

Em razão das reclamações acerca da morosidade (lentidão) da Justiça, o Judiciário Brasileiro passou por uma reforma, estabelecida pela Emenda Constitucional n. 45 (EC/45), que é uma das tentativas na busca de dar respostas mais céleres aos jurisdicionados, com expectativa de que suas alterações possam gerar transformações para impor uma efetividade quantitativa e qualitativa com o Sistema Judiciário Nacional. Nesse sentido, a EC n. 45 tem incidência na questão do acesso à justiça, mas principalmente sobre a tutela jurisdicional que passa a "dever ser" tempestiva, visto que "[...] não basta apenas garantir o acesso ao poder judiciário e aos meios adequados para defesa, pois para satisfazer o jurisdicionado é preciso ainda que a tutela pleiteada seja conferida dentro de um razoável prazo, sob pena de se tornar totalmente inútil." (SPALDING, 2005, p. 32).

Isso porque a EC n. 45 inseriu de forma expressa o princípio da celeridade processual, ao acrescentar mais um direito fundamental aos 77 incisos já existentes no Artigo $5^{\circ}$. Com essa Emenda, foi acrescentado à Constituição Federal o inciso LXXVIII, o qual refere que "[...] a todos, no âmbito judicial e administrativo, são assegurados a razoável duração do processo e os meios que garantam a celeridade de sua tramitação." (BRASIL, 1988). 
Busca-se ao menos tornar razoável a duração do processo e concretizar o princípio da garantia constitucional do exercício da tutela jurisdicional ou princípio da inafastabilidade do Poder Judiciário, conforme previsto no inciso XXXV do Artigo $5^{\circ}$ da $\mathrm{CF} / 88$, ou seja, a garantia do acesso à justiça, que é a mais fundamental modalidade de direitos humanos. Observa-se que é a partir da codificação dos Direitos Humanos que o fenômeno da razoável duração do processo passa a ser inserido tanto em Tratados, Pactos ou Convenções Internacionais, quanto nas Constituições, que também passaram a incorporar em seus textos o capítulo dos direitos e garantias fundamentais.

Destaca-se que o foco original de disseminação da preocupação com a razoável duração do processo, em proporção mundial, ocorreu com a Convenção Americana sobre os Direitos Humanos de 1969, conhecida como Pacto de San José da Costa Rica, aderida pelo Brasil em 25 de setembro de 1992, ressalvadas as cláusulas facultativas do Artigo 45, $1^{\circ}$ e Artigo 62, $1^{\circ}$ (COMPARATO, 2010). Nesse sentido, observa-se no item 1 do Artigo $8^{\circ}$, que trata das garantias judiciais, que:

1. Toda pessoa terá o direito de ser ouvida, com as devidas garantias e dentro de um prazo razoável, por um juiz ou Tribunal competente, independente e imparcial, estabelecido anteriormente por lei, na apuração de qualquer acusação penal formulada contra ela, ou na determinação de seus direitos e obrigações de caráter civil, trabalhista, fiscal ou de qualquer outra natureza. (PIOVESAN, 2012, p. 628, grifo nosso).

Dessa forma, a EC n. 45 não trouxe inovação em relação à garantia da razoável duração do processo, visto que o Brasil já era signatário do mencionado Pacto desde 1992. Todavia, ao introduzir essa determinação no Artigo $5^{\circ}$ da Constituição Federal, instituiu esse princípio como um direito fundamental, o qual deve ter aplicação imediata, pois conforme disposto no parágrafo $1^{\circ}$ do Artigo $5^{\circ}$ da Carta Constitucional Brasileira, “[...] as normas definidoras dos direitos e garantias fundamentais têm aplicação imediata."

Por esse motivo, e considerando que a protelação e a morosidade comprometem a útil e justa entrega da prestação jurisdicional, necessário adaptar o Judiciário Brasileiro para que de fato dê ao processo uma duração razoável. Mas o que é o tempo razoável para a duração de um processo judicial? Como já foi tentado esclarecer o conceito de tempo, necessário agora se faz buscar entender qual o sentido da palavra "razoável", no contexto de "tempo razoável”, ou de duração razoável do processo. Assim, segundo a própria definição do dicionário, razoável significa ser aceitável, que tem bom senso, não excessivo, entre outras significações. Todavia, conforme Moro (2012), não é na literalidade que se encontra a aplicação de se proporcionar a "razoável duração do processo", mas na interpretação teleológica e sistemática do texto. Para o autor, na prática, caberá ao próprio Judiciário estabelecer o que é razoável para si, mas como essa disposição constitucional representa cristalino direito fundamental, de aplicação imediata, os advogados deverão atuar para exigir a aplicação dos princípios da celeridade e da duração razoável do processo. 
Para Silva (2005), há duas formas de concretização desse mandamento constitucional: promover alterações na legislação federal, para tornar mais efetivo o acesso à justiça e os tribunais (e analogicamente dos entes administrativos) atuarem de forma incisiva, para que tomem providências em face de eventuais membros desidiosos. Já segundo Rodrigues (2005, p. 289), a ideia de "razoável duração do processo" deve ser interpretada considerando duas hipóteses: “[...] a) tempo razoável é o tempo legal, expressamente previsto na legislação processual; b) tempo razoável é o tempo médio efetivamente despendido no país para cada espécie concreta de processo.” Nesse sentido, segundo Fabiana Marion Spengler (2010, p. 217):

A primeira opção reproduz um critério objetivo, sofrendo o desgaste de nem sempre existir, em cada etapa processual, tempo previamente definido em lei. Já a adoção da segunda hipótese traz a negativa da garantia constitucional, pois a média de duração dos processos no Brasil hoje se encontra muito acima do legal e do razoável.

Nessa mesma linha, Bolzan de Morais (2005, p. 16), discutindo sobre a expressão "prazo razoável", afirma que o seu sentido deve ser "[...] preenchido no caso concreto, tendo como indicativo a melhor e maior realização da garantia de acesso à justiça na perspectiva de acesso a uma resposta à questão posta qualitativamente adequada e em tempo quantitativamente aceitável." Dessa forma, observa-se que a busca pela celeridade processual deve considerar uma resposta qualificada aos conflitos, pois não basta que uma decisão judicial seja justa e correta, ela deve ser tempestiva, pois se torna ineficaz quando chega tarde, ou seja, "[...] quando é entregue ao jurisdicionado no momento em que não lhe interessa nem mesmo o reconhecimento e a declaração do direito pleiteado." (SPENGLER, 2010, p. 218).

Sobre o assunto, Silva (2005, p. 432) afirma que

[...] a norma acena para a regra de razoabilidade cuja textura aberta deixa amplas margens de apreciação, sempre em função de situações concretas. Ora, a forte carga de trabalho dos magistrados será, sempre, um parâmetro a ser levado em conta na apreciação da razoabilidade da duração dos processos a seu cargo.

Todavia, embora o volume de processos que tramita no Judiciário inviabiliza, muitas vezes, a observância de um período de tempo agradável aos interessados, a obstrução dos órgãos do Judiciário pela quantidade de processos não constitui, por si só, motivação objetiva para a demora injustificável de alguns provimentos.

Em linhas gerais, há um consenso de que para que haja uma razoável duração do processo é necessário que o processo tramite sem dilações indevidas. Para ajudar nessa compreensão, observa-se que o posicionamento da Corte Europeia dos Direitos do Homem estabelece três critérios para verificar a razoável duração do processo: a complexidade do assunto, o comportamento dos litigantes e de seus procuradores e a atuação do órgão jurisdicional (BELO, 2010). 
A complexidade da causa é aferida pelas peculiaridades das questões fáticas ou jurídicas, bem como pelo número de pessoas envolvidas. No comportamento das partes está incluída a investigação sobre os responsáveis pelo prolongamento indevido das causas, trabalhando com temas como o abuso de direito, boa-fé e lealdade processuais, pois não adianta reformas e técnicas para aumentar a efetividade e acelerar os feitos se os sujeitos envolvidos no processo se desvirtuarem do objetivo da justiça, utilizando-se de fins ilícitos ou com manifesta má-fé na atuação com o processo. Em relação à atuação das autoridades, é analisada a conduta dos juízes e serventuários, isto é, dos agentes públicos que lidam com o processamento e julgamento dos feitos, o que deve ser feito de forma qualitativa, pois não basta averiguar o tempo transcorrido do processo, é necessário verificar como esse tempo foi empregado, para verificar se foi compatível com a atividade jurisdicional prestada.

Conforme Belo (2010), verifica-se que os critérios especificados pela Corte Europeia de Direitos Humanos afastam a doutrina da fixação de prazos para a verificação da razoabilidade do tempo processual. Essa dificuldade de estabelecer prazos máximos é em razão de que o "[...] exame da razoabilidade é concreto e não abstrato" (NICOLITT, 2006, p. 26 apud BELO, 2010, p. 62). Dessa forma, a "[...] prestação da justiça em tempo hábil não possui uma dimensão temporal delimitada, justamente por envolver casos concretos. Há que se mensurar, sempre, a celeridade processual com as demais garantias do due processo of Law." (BELO, 2010, p. 62). Assim, para que o processo tenha duração razoável, justa, devem ser consideradas as variáveis concretas.

E no desiderato de conferir maior efetividade ao processo, a adoção de novas tecnologias desempenha papel fundamental, sendo o processo eletrônico uma forma de efetivar a razoável duração do processo, propiciando uma prestação jurisdicional mais rápida e eficiente, o que será visto a seguir.

\title{
3 Processo eletrônico como forma de efetivação do princípio da celeridade e do acesso à justiça
}

Há três décadas, José Guilherme Merquior já refletia sobre as inovações tecnológicas na sociedade pós-industrial:

\begin{abstract}
O impacto da ciência na tecnologia constitui sabidamente o fulcro do desdobramento da sociedade industrial em "pós-industrial". No limiar do século XXI, nas economias de ponta, o avanço da eletrônica e da informática já começa a esboçar a superação de um dos traços institucionais mais típicos do industrialismo: a disjunção entre o local de residência e do trabalho, manual ou não. Graças à difusão dos computadores e das telecomunicações, um número crescente de funções de escritório passará a poder ser realizado em casa, dentro de ritmos e horários livremente fixados pelo assalariado [...] Com o progresso da automação, o tempo de lazer tende cada vez mais a aumentar face ao tempo de trabalho. (MERQUIOR, 1982, p. 18-19 apud LIMA, 2012).
\end{abstract}

Sobre os novos desafios trazidos pela revolução tecnológica no campo do Direito, Veiga (2009, p. 7-8) anotou que: 


\begin{abstract}
A revolução tecnológica que o computador operou na sociedade é de tal modo significativa que é por muitos considerada a sucessora da Revolução Industrial. Foi necessário esperar, cerca de três séculos, para que um fenômeno com aquela amplitude eclodisse, tendo proporcionado importantes transformações sociais, a mais importante das quais, é a transformação da informação de átomos para bits, o "ADN da informação", que tem atualmente uma nova configuração. A informação ainda continua a ser fornecida, em larga medida, em átomos: jornais, revistas e livros. O trilho, contudo, é irreversível: a completa "digitalização da sociedade", a transmissão exclusiva da informação através da vida digital.
\end{abstract}

A estrutura do Judiciário, para garantir o efetivo acesso à justiça, precisa acompanhar a modernização da sociedade com o uso das novas tecnologias, principalmente a informática. Assim, o processo não pode se modernizar somente em relação às leis ou às atitudes de seus operadores. É necessário materializar o seu desenvolvimento, no mundo globalizado e dinâmico em que vivemos, por meio do uso das novas tecnologias das informações. Nesse sentido, surge o processo eletrônico, que veio para ficar e contribuir com o acesso de todos a uma ordem jurídica justa, ágil e eficaz.

Observa-se que o processo eletrônico vem ao encontro da terceira onda renovatória proposta por Cappelletti e Garth (1988) na obra "Acesso à justiça”, pois os autores propõem meios alternativos de solução de conflitos, com a simplificação dos procedimentos judiciais e a ampliação do acesso à justiça; a informatização do Judiciário e a instituição do processo eletrônico estão inseridos nesse cenário, pois se apresentam como mecanismos simples e ágeis de aproximação do cidadão à justiça.

Assim, no encontro do ponto comum entre as Novas Tecnologias de Informação e Comunicação (NITCs) e a busca pela celeridade na tramitação dos processos judiciais, em 19 de dezembro de 2006, foi promulgada a Lei n. 11.419 (Lei do Processo Eletrônico), dispondo sobre a informatização do processo judicial, a qual entrou em vigor em 19 de março de 2007. Essa Lei alterou a Lei n. 5.869/73 (Código de Processo Civil), possibilitando modificações importantes na organização da prestação de serviços jurisdicionais. Embora o comando normativo não tenha apresentado natureza impositiva, estabeleceu as condições necessárias para a alteração na tramitação do processo, buscando a plena utilização dos recursos tecnológicos disponíveis.

O processo virtual veio adaptar o processo para torná-lo mais célere e eficaz, na busca de um efetivo acesso à justiça. Dessa forma, as alterações mais significativas trazidas pela Lei n. 11.419/2006 dizem respeito ao combate à morosidade judicial. Entretanto, como os prazos, os recursos, as ações e os procedimentos se mantiveram os mesmos, não houve uma transformação radical no Código de Processo Civil. Em verdade, as modificações ocorreram especialmente quanto à estrutura de tramitação dos procedimentos, pois os autos virtuais podem ser acessados a qualquer momento (24 horas por dia), por qualquer das partes, inclusive de forma simultânea, sem qualquer vinculação aos dias e horários de funcionamento das unidades judiciárias.

Com a Lei do Processo Eletrônico, definitivamente passou a ser admitido o uso de meios eletrônicos na tramitação de processos judiciais, comunicação de atos 
e transmissão de peças processuais, com aplicação, indistintamente, aos processos civil, penal e trabalhista, bem como aos juizados especiais, em qualquer grau de jurisdição, conforme previsto em seu Artigo $1^{\circ}$ e parágrafos, a seguir transcritos:

Art. 1o O uso de meio eletrônico na tramitação de processos judiciais, comunicação de atos e transmissão de peças processuais será admitido nos termos desta Lei.

$\S 1$ o Aplica-se o disposto nesta Lei, indistintamente, aos processos civil, penal e trabalhista, bem como aos juizados especiais, em qualquer grau de jurisdição.

$\S 2^{\circ}$ Para o disposto nesta Lei, considera-se:

I - meio eletrônico qualquer forma de armazenamento ou tráfego de documentos e arquivos digitais;

II - transmissão eletrônica toda forma de comunicação a distância com a utilização de redes de comunicação, preferencialmente a rede mundial de computadores;

III - assinatura eletrônica às seguintes formas de identificação inequívoca do signatário:

a) assinatura digital baseada em certificado digital emitido por Autoridade Certificadora credenciada, na forma de lei específica;

b) mediante cadastro de usuário no Poder Judiciário, conforme disciplinado pelos órgãos respectivos.

A lei que instituiu o processo eletrônico (Lei n. 11.419/2006) autorizou, em seu Artigo $8^{\circ}$, os órgãos do Poder Judiciário a desenvolverem sistemas eletrônicos de processamento de ações judiciais por meio de autos total ou parcialmente digitais, utilizando, preferencialmente, a rede mundial de computadores e o acesso por meio de redes internas e externas. Também permitiu aos órgãos do Poder Judiciário regulamentar a lei do processo eletrônico, no que couber, no âmbito de suas respectivas competências, conforme disposto no Artigo 18. Ainda, mediante seu Artigo 19, convalidou os atos processuais praticados por meio eletrônico até a data de publicação da Lei, desde que tenham atingido sua finalidade e não tenha havido prejuízo para as partes. Isso porque já havia órgãos utilizando o meio eletrônico para a prática de atos processuais antes mesmo da promulgação da referida lei.

Nessa linha da busca pela celeridade com a utilização da informatização e virtualização dos autos processuais, verifica-se, no site institucional (PORTAL, 2012), que o Tribunal Regional Federal da $4^{\mathrm{a}}$ Região (TRF4) ${ }^{1}$ criou o processo eletrônico antes mesmo da Lei n. 11.419/2006, por meio da Resolução n. 13, de 11 de março de 2004, que estabeleceu normas para o funcionamento do processo eletrônico

\footnotetext{
1 O Tribunal Regional Federal da $4^{\text {a }}$ Região (TRF4), com sede em Porto Alegre, tem jurisdição nos Estados do Rio Grande do Sul, Santa Catarina e Paraná. O TRF4 é composto por 27 Desembargadores Federais, escolhidos entre os Juízes Federais de $1^{a}$ Instância, membros do Ministério Público e representantes da Ordem dos Advogados do Brasil, nomeados pelo Presidente da República, nos termos da Constituição Federal. Os magistrados julgam recursos em causas decididas por juízes federais de primeiro grau em ações que envolvam a União Federal, autarquias e empresas públicas. No TRF4 são analisados recursos em processos administrativos (civil e comercial), criminais, previdenciários e tributários.
} 
nos Juizados Especiais Federais (JEFs) no âmbito da Justiça Federal ${ }^{2}$ da $4^{\text {a }}$ Região. Após, com a Resolução n. 75, de 16 de novembro de 2006, o processo eletrônico foi adotado para todas as ações de competência dos JEFs da $4^{\text {a }}$ Região. Na sequência, foi prevista a implantação do processo eletrônico de forma gradativa também para os processos do juízo comum cível e criminal, no âmbito da Justiça Federal de $1^{\circ}$ e $2^{\circ}$ graus da $4^{\text {a }}$ Região, conforme a Resolução n. 64, de 17 de novembro de 2009 , do TRF4. Posteriormente, o TRF4 editou a Resolução n. 17, de 26 de março de 2010, regulamentando uma nova versão do processo judicial eletrônico no âmbito da Justiça Federal da $4^{\text {a }}$ Região, fazendo com que todas as ações do juízo comum cível e criminal, ajuizadas a partir dessa nova versão, tramitem pelo meio eletrônico, remanescendo em meio físico (papel) apenas as ações previamente ajuizadas.

Ainda no site institucional do TRF4 (PORTAL, 2012), verifica-se que os principais objetivos do processo eletrônico são a facilitação do trabalho dos advogados e procuradores dos órgãos públicos, a melhoria da qualidade de atendimento às partes, a agilização dos serviços dos servidores, a segurança e a rapidez na atuação dos magistrados e a agilização no trâmite dos processos, tendo como meta principal a economia e a celeridade na tramitação dos processos. Salienta-se, ainda, como uma das principais vantagens trazidas pelo sistema, o fato de possibilitar o acesso instantâneo aos dados do processo, que pode ocorrer de qualquer lugar do mundo, via web, ou seja, um acesso sem barreiras/fronteiras. Ademais, permite uma maior interação do Poder Judiciário com a sociedade, possibilitando que a Justiça vá ao encontro do cidadão (Exemplo: quiosques de atendimento em praças, prefeituras, repartições públicas, universidades, etc.). Também os advogados podem acessar os processos do seu escritório ou mesmo em viagem, podem praticar atos processuais,

\footnotetext{
2 A Justiça Federal foi criada pelo Decreto n. 848, de 11 de outubro de 1890. Sua instituição foi confirmada pela Constituição dos Estados Unidos do Brasil, de 1891. Após ser suprimida pelo Presidente Getúlio Vargas, em 1937, durante o Estado Novo, a Justiça Federal de primeira instância somente seria reimplantada durante o Regime Militar, recriada pela Lei n. 5.010, de 30 de maio de 1966. No Rio Grande do Sul, a Justiça foi instalada nos meses de maio e junho de 1967. Com o passar do tempo, a instituição foi se ampliando e interiorizando. As primeiras varas federais no interior foram implantadas em Rio Grande, Santa Maria e Passo Fundo, no ano de 1987. Em 30 de março de 1989 foi instalado, em Porto Alegre, o Tribunal Regional Federal da $4^{\text {a }}$ Região, responsável pelo julgamento dos recursos originários dos Estados do Rio Grande do Sul, Santa Catarina e Paraná. Em maio de 1997, a sede da Seção Judiciária mudou-se para a Rua Otavio Francisco Caruso da Rocha, 600, no centro administrativo federal, com o Parque Maurício Sirotsky Sobrinho (Parque da Harmonia), em Porto Alegre, onde até hoje se encontra fixada. A Seção Judiciária do Rio Grande do Sul, com a de Santa Catarina e a do Paraná, formam a primeira instância da $4^{\mathrm{a}}$ Região, vinculando-se ao Tribunal Regional Federal da $4^{\text {a }}$ Região, órgão de segunda instância, sediado em Porto Alegre.

A Justiça Federal é o órgão do Poder Judiciário que tem como missão a pacificação dos conflitos que envolvem os cidadãos e a Administração Pública Federal, em diversas áreas. Nos processos da Justiça Federal aparecem, de um lado, os particulares e, de outro, a União, as empresas públicas, autarquias e fundações públicas federais ou os conselhos de fiscalização profissional. Julgam-se, diariamente, na Justiça Federal, processos referentes ao meio ambiente, previdência social, direito tributário, licitações, contratos de financiamento habitacional firmados com empresas públicas ou autarquias, questões relativas a concursos e a imóveis da União, entre outras. Em matéria penal, a Justiça Federal tem na sua competência o julgamento de crimes fiscais, de lavagem de dinheiro, de tráfico internacional de entorpecentes e diversos outros. São comuns na Justiça Federal os conflitos de massa, que atingem um número muito expressivo de pessoas. Assim, são as ações sobre a correção monetária do FGTS, as ações previdenciárias, os processos tributários e os que tratam dos financiamentos da casa própria. Esses processos ingressam individualmente ou sob a forma coletiva. A competência da Justiça Federal de primeira instância está definida no Artigo 109 da Constituição (PORTAL, 2012).
} 
inclusive, com redução de custos. Ainda, os juízes têm facilidade de acesso, podendo resolver questões urgentes mesmo sem comparecer à sede da Justiça.

Como pioneiro no Brasil na implantação do processo eletrônico para todas as ações, o Tribunal Regional Federal da $4^{\text {a }}$ Região pode ser tomado como exemplo e "laboratório" para a análise dos resultados trazidos com a utilização do processo eletrônico. Nesse sentido, observando uma experiência muito próxima, que já "nasceu eletrônica", percebemos que o Juizado Especial Federal Avançado (JEFA) ${ }^{3}$ de Ijuí (PREFEITURA DE IJUÍ - PODER EXECUTIVO, 2012) ${ }^{4}$ aproximou a Justiça Federal da comunidade ijuiense, demonstrando que é possível dizer que o processo eletrônico está atingindo seus objetivos, especialmente quanto à efetivação do acesso à justiça. Isso porque, como resultados práticos da utilização do processo eletrônico, verifica-se que, além de facilitar o acesso à justiça, permite agilidade na tramitação dos processos, redução de custos e ganho em produtividade, tudo isso em consonância com o Planejamento Estratégico Nacional e o Planejamento da Justiça Federal da $4^{\mathrm{a}}$ Região.

A informatização do Judiciário, nos dizeres de Fortes (2012) "[...] contribui de forma profícua para que todas as ondas de desenvolvimento do acesso à justiça se efetivem", uma vez que "[...] surge a facilitação da admissão de demandas propostas por pessoas necessitadas que não precisam de advogado para ingressar, por exemplo, com ações nos Juizados Especiais, locais onde existem funcionários que colocam a termo eletronicamente o pedido do indivíduo." Ademais, "[...] a digitalização melhora a comunicação de atos em âmbito nacional e a defesa de interesses supraindividuais", visto que valoriza o cliente do poder jurisdicional, entre outras coisas, com maior publicidade dos atos processuais, que ficam disponíveis na rede mundial de computadores; maior celeridade, pois atos de cartório deixam de tomar tanto tempo das varas; economia, pois o processo eletrônico é mais barato e, principalmente, celeridade na resolução dos conflitos, com a busca da concretização do princípio da duração razoável do processo.

Assim, apesar de certamente não ser o processo eletrônico a resposta para todos os problemas de nosso sistema jurídico, ele é um meio possível de amenizar a burocracia existente no ordenamento jurídico brasileiro, de modo a viabilizar a efetivação do tão almejado direito fundamental de acesso à justiça.

\section{Conclusão}

Com o presente artigo, verificou-se que o acesso à justiça é um direito humano fundamental, podendo ser chamado de o mais básico dos direitos, pois é ao

\footnotetext{
3 Com a Resolução n. 90 do TRF, de 15 de agosto de 2012, a partir de 24 de setembro de 2012, o então JEFA teve sua competência ampliada e passou a ser denominado Unidade Avançada de Atendimento da Justiça Federal em Ijuí. 4 O Município de Ijuí está localizado a uma latitude $28^{\circ} 23$ ' $16^{\prime \prime}$ Sul e a uma longitude $53^{\circ} 54$ '53" Oeste, estando a uma altitude de 328 metros do nível do mar. Possui $689 \mathrm{Km}^{2}$ de área e uma população de 79.396 habitantes, segundo dados do Censo 2012.
} 
redor dele que convergem todos os demais. Esse acesso não é apenas de peticionar aos Órgãos Jurisdicionais, mas o dever de ser garantido o acesso a uma ordem jurídica justa. Para isso, o processo deve possuir uma duração razoável, com resposta ao conflito em tempo adequado, pois não adianta uma decisão judicial justa e correta que chegue tarde e se torne ineficaz.

Considerando que um dos entraves para a efetivação do processo diz respeito à sua duração, foi avaliada a questão do tempo do processo, bem como brevemente analisado o princípio da celeridade e da razoável duração do processo. Nesse sentido, observou-se que já existia a previsão de prazo razoável do processo no Pacto de San José da Costa Rica, assinado pelo Brasil em 1992. Todavia, a EC n. 45/2004 elevou a direito fundamental a garantia da razoável duração do processo, ao introduzi-la no inciso LXXVIII do Artigo $5^{\circ}$ da Constituição Federal.

E acompanhando as evoluções tecnológicas, com o principal objetivo de proporcionar aos jurisdicionados uma maior celeridade dos procedimentos, ajudando a efetivar o acesso à justiça, surge o processo eletrônico, que traz como algumas de suas vantagens a facilidade de acesso à justiça e a agilização da tramitação processual. Nesse sentido, analisando os resultados práticos da utilização do processo eletrônico, por meio da experiência do Tribunal Regional Federal da $4^{\mathrm{a}}$ Região, o qual foi o pioneiro na implantação do processo eletrônico para todas as ações, verifica-se que ele está atingindo os seus objetivos, especialmente quanto a ajudar na efetivação do acesso à justiça. Isso porque, além de facilitar o acesso à justiça, permite agilidade na tramitação dos processos, redução de custos e ganho em produtividade, tudo isso em consonância com o Planejamento Estratégico Nacional e também o Planejamento da Justiça Federal da $4^{\text {a }}$ Região.

\section{Referências}

BELO, Duína Porto. A razoável duração do processo como instrumento de acesso à justiça. Revista Direito e Desenvolvimento, ano 1, n. 2, p. 55-68, 2010.

BOLZAN DE MORAIS, José Luis. As crises do Judiciário e o acesso à justiça. In: AGRA, Walber de Moura. Comentários à reforma do poder judiciário. Rio de Janeiro: Forense, 2005.

BRASIL. Constituição. República Federativa do Brasil de 1988. Brasília, DF: Senado Federal, 1988. Disponível em: < http://www.planalto.gov.br/ccivil_03/constituicao/ constitui\%C3\%A7ao.htm>. Acesso em: 06 ago. 2012.

BRASIL. Emenda Constitucional n. 45, de 30 de dezembro de 2004. Altera dispositivos dos arts. $5^{\circ}, 36,52,92,93,95,98,99,102,103,104,105,107,109,111,112,114$, 115, 125, 126, 127, 128, 129, 134 e 168 da Constituição Federal, e acrescenta os arts. 103-A, 103B, 111-A e 130-A, e dá outras providências. Diário Oficial da União, Brasília, DF, 30 dez. 2004. Disponível em: <http://www.planalto.gov.br/ccivIl_03/Constituicao/Emendas/Emc/emc45.htm>. Acesso em: 12 ago. 2012. 
BRASIL. Lei n. 11.419, de 19 de dezembro de 2006. Dispõe sobre a informatização do processo judicial; altera a Lei n. 5.869, de 11 de janeiro de 1973 - Código de Processo Civil; e dá outras providências. Diário Oficial da União, Brasília, DF, 19 dez. 2006. Disponível em: <http://www.planalto.gov.br/ccivil_03/_ato2004-2006/2006/lei/ 111419.htm >. Acesso em: 12 ago. 2012.

CAPPELLETTI, Mauro; GARTH, Brian. Acesso à Justiça. Tradução e revisão Ellen Gracie Northfleet. Porto Alegre: Sérgio Antonio Fabris, 1988.

CICHOCKI NETO, José. Limitações ao acesso à justiça. Curitiba: Juruá, 2001.

CINTRA, Antônio Carlos de Araújo; GRINOVER, Ada Pellegrini; DINAMARCO, Cândido Rangel. Teoria Geral do Processo. 20. ed. rev. e atual. São Paulo: Malheiros, 2004.

COMPARATO, Fábio Konder. A afirmação histórica dos direitos humanos. 7. ed. rev. e ampl. São Paulo: Saraiva, 2010.

DARÓS, Vilson. Planejamento Estratégico do Tribunal Regional Federal da $4^{a}$ Região. Porto Alegre: TRF - $4^{\mathrm{a}}$ Região, 2009.

FORTES, Rafael Costa. Informatização do Judiciário e o processo eletrônico. Jus Navigandi, Teresina, ano 14, n. 2374, 2009. Disponível em: < http://jus.com.br/revista/texto/14101>. Acesso em: 21 fev. 2012.

HOUAISS, Antônio; VILLAR, Mauro de Salles. Minidicionário Houaiss da língua portuguesa. Elaborado no Instituto Antônio Houaiss de Lexicografia e Banco de Dados da Língua Portuguesa S/C Ltda. 3. ed. rev. e ampl. Rio de Janeiro: Objetiva, 2008.

LIMA, Rogério Medeiros Garcia de. Implantação do processo eletrônico na perspectiva dialógica. Jus Navigandi, Teresina, ano 17, n. 3308, 2012. Disponível em: <http:/jus.com.br/revista/texto/22256>. Acesso em: 24 jul. 2012.

MORO, Luís Carlos. Onde está a razoabilidade. Como se define a "razoável duração do processo", prevista na Reforma. Consultor Jurídico. Disponível em: < http:// www.conjur.com.br/2005-jan-23/definir_razoavel_duracao_processo >. Acesso em: 11 ago. 2012.

NALINI, José Renato. O juiz e o acesso à justiça. 2. ed. rev. atual. e ampl. São Paulo: Revista dos Tribunais, 2000.

OST, François. O Tempo do Direito. Tradução Élcio Fernandes. Revisão técnica Carlos Aurélio Mota de Souza. 1. ed. Bauru: Edusc, 2005. 
OST, François. O Tempo do Direito. Tradução Maria Fernanda Oliveira. 1. ed. Lisboa: Instituto Piaget, 1999.

PIOVESAN, Flávia. Direitos humanos e o direito constitucional internacional. 13. ed. rev. e atual. São Paulo: Saraiva, 2012.

PORTAL da Justiça Federal da $4^{\mathrm{a}}$ Região. Coordenadoria dos Juizados Especiais Federais. COJEF - Processo eletrônico. Disponível em: < http://www.trf4.jus.br/trf4/ institucional/institucional.php? no=164>. Acesso em: 28 fev. 2012.

PREFEITURA DE IJUÍ - PODER EXECUTIVO. Apresentação. Disponível em: <http://www.ijui.rs.gov.br/prefeitura/index/1>. Acesso em: 05 set. 2012.

RODRIGUES, Horácio Wanderlei. Acesso à justiça e prazo razoável na prestação jurisdicional. In: WAMBIER, Teresa Arruda Alvin (Org.). Reforma do Judiciário. Primeiras reflexões sobre a Emenda constitucional n. 45/2004. 1. ed. São Paulo: Revista dos Tribunais, 2005.

SILVA, José Afonso da. Curso de Direito Constitucional Positivo. 22. ed. rev. e atual. São Paulo: Malheiros, 2003.

SILVA, José Afonso da. Curso de Direito Constitucional Positivo. 24. ed. rev. e atual. São Paulo: Malheiros, 2005.

SPALDING, Alessandra Mendes. Direito Fundamental à Tutela Jurisdicional Tempestiva à Luz do Inciso LXXVIII do Art. $5^{\circ}$ da CF Inserido pela EC n. 45/2004. In: WAMBIER, Teresa Arruda Alvin (Org.). Reforma do Judiciário. Primeiras reflexões sobre a emenda constitucional n. 45/2004. 1. ed. São Paulo: Revista dos Tribunais, 2005.

SPENGLER, Fabiana Marion. Da Jurisdição à Mediação. Por uma outra cultura no tratamento de conflitos. 1. ed. Ijuí: Ed. Unijuí, 2010.

SPENGLER, Fabiana Marion; SPENGLER NETO, Theobaldo. O acesso à justiça como direito humano básico e a crise da jurisdição no Brasil. Scientia Iuris (UEL), v. 15, p. 53-74, 2011.

VEIGA, Armando. Legislação de Direito da Informática. 2. ed. Coimbra: Ed. Coimbra, 2009.

VENTURA, Deisy. Monografia Jurídica: uma visão prática. 1. ed. Porto Alegre: Livraria do Advogado, 2000.

Data de submissão: 26 de fevereiro de 2013 Avaliado em: 04 de abril de 2013 (Avaliador A) Avaliado em: 10 de maio de 2013 (Avaliador B) Aceito em: 17 de novembro de 2014 